\title{
Studies on Thermal and Morphological Behavior of Siliconized Epoxy Bismaleimide Matrices
}

\author{
A. ASHOK KUMAR,' M. ALAGAR,' R. M. V. G. K. RAO ${ }^{2}$ \\ 'Department of Chemical Engineering, Anna University, Chennai-600 025, India \\ 2 Fibre Reinforced Plastic-Pilot Plant, National Aerospace Laboratories, Bangalore-560 017, India
}

Received 17 April 2000; accepted 5 September 2000

Publishedønline 12 June 2001

\begin{abstract}
Novel bismaleimide-modified siliconized epoxy intercrosslinked network systems were developed. Siliconized epoxy systems containing 5,10 , and $15 \%$ siloxane units were prepared using epoxy resin and hydroxyl-terminated polydimethylsiloxane (HTPDMS) with $\gamma$-aminopropyltriethoxysilane ( $\gamma$-APS) as a compatibilizer and dibutyltindilaurate as a catalyst. The siliconized epoxy systems were further modified with 5,10 , and $15 \%$ (wt \%) of bismaleimide $\left[\left(N, N^{\prime}\right.\right.$-bismaleimido- $4,4^{\prime}$-diphenylmethane) (BMI)] and cured by diaminodiphenylmethane (DDM). Differential scanning calorimetry (DSC), thermogravimetric analysis (TGA), and heat-distortion temperature measurement of the matrix samples were carried out to assess their thermal behavior. DSC thermograms of the BMI-modified epoxy systems show unimodel reaction exotherms. The glass transition temperature $(T$ ) of the cured BMI-modified epoxy and siliconized epoxy systems increases with increasing BMI content. Thermogravimetric analysis and heat-distortion temperature measurements indicate that the thermal degradation temperature and heat-distortion temperature of the BMI-modified epoxy and siliconized epoxy systems increase with increasing BMI content. The morphology of the BMImodified siliconized epoxy systems was also studied by scanning electron microscopy (SEM). (C) 2001 John Wiley \&, Sons, Inc. J Appl Polym Sci 81: 2330-2346, 2001
\end{abstract}

Key words: $\gamma$-APS; dibutyltindilaurate; diaminodiphenylmethane; siliconized epoxy resin; BMI-modified siliconized epoxy resin; glass transition temperature; thermal stability; heat-distortion temperature; SEM micrograph

\section{INTRODUCTION}

The development of modern technology lays emphasis on reliable high-performance composite materials having light weight with excellent thermal and mechanical properties for applications such as a vacuum (space) or strong electric, magnetic, or irradiation fields under adverse environ-

\footnotetext{
Correspondence to: M. Alagar.

Contract grant sponsor: Council of Scientific Industrial Research (CSIR).

Journal of Applied Polymer Science. Vol. 81, 2330-2346 (2001) (1) 2001 Juhn Wilcy \& Suns, Inc.

mental conditions. ${ }^{1}$ Epoxy resin-based composit $\epsilon$ are widely used as laminates for printed circu boards, aerospace, ballistic, and engineerin hardware components, pollution-control equil ment, automotive parts, electrical component and rehabilitation products, etc., because of the excellent bonding, thermal, and mechanical chas acteristics. ${ }^{2-7}$

However, the mechanical and thermal chara teristics of epoxy matrices are not sufficient 1 meet the requirements of high-performans structural products. To enhance toughness an thermal stability in order to make it suitable fs high-performance aerospace and engineering at 
Cabie I Composition of Curing Agent, jompatiblizer, and Catalyst

\begin{tabular}{ccccc}
\hline $\begin{array}{c}\text { Epoxy } \\
\text { (wt \%) }\end{array}$ & $\begin{array}{c}\text { Siloxane } \\
\text { (wt \%) }\end{array}$ & $\begin{array}{c}\text { Amount } \\
\text { of Curing } \\
\text { Agent }(\mathrm{g})\end{array}$ & $\begin{array}{c}\text { Compatiblizer } \\
(\mathrm{g})\end{array}$ & $\begin{array}{c}\text { Catalyst } \\
(\mathrm{g})\end{array}$ \\
\hline 100 & 0 & 27 & - & - \\
-100 & 5 & 27 & 0.05 & 0.1 \\
100 & 10 & 27 & 0.09 & 0.1 \\
100 & 15 & 27 & 0.14 & 0.1 \\
\hline
\end{tabular}

plications, modification of epoxy resin is essential. Several attempts have been made to modify epoxy resin using flexible polymeric materials, namely, ATB CTBN, HTBN, nitrile rubber, and polyacrylatus. ${ }^{7-9}$ The introduction of these polymeric materials into epoxy resin improved its impact characteristics but failed to enhance the glass transition temperature, service temperature, resistance to weather, modulus, and reduce the moisture-absorption characteristics of epoxy resin to a level required for high-performance applicat:ons.

An intercrosslinking network mechanism provides an effective method of obtaining matrix materials with a single glass transition temperature when compared with polymer blends, which normally exhibit multiple-glass-transitions -due to thermodynamic incompatibility of the component. involved. Tqughening of epoxy resin, with polyn: rs having a flexible backbones, is expected to improve the impact strength and to enhance strain to fracture. To achieve this objective, the development of an intercrosslinked polymer network, having flexible and rigid molecular segments, can be considered as an attractive method. The components of choice for epoxy modifications are the hydroxyl derivatives of polydimethylsiloxane and bismalcimide because of their flexible and rigid molecular skeletons, respectively.

Hydroxyl-terminated polydimethylsiloxane (HTPDMS) possesses high thermal and thermooxidative stability, high moisture resistance, good dielectric properties, and UV and chemical resistance. ${ }^{10-18}$ In our earlier work, it was observed that siloxane incorporation into epoxy resin improves impact strength, with an insignificant change in the glass transition behavior, and reduces the tensile characteristics. ${ }^{19}$ The improvement in thermomechanical properties of epoxy resin was observed with the introduction of bismaleimide. ${ }^{20-24}$ Bismaleimides possess high crosslinking ability, high glass transition temperature, high thermal stability, high char yield, excellent fire resistance, superior specific strength and specific modulus, and low water absorption.

Hence, in the present study, an attempt was made to improve both the toughness and thermal behavior of epoxy resin without an appreciable loss in strength properties by forming an intercrosslinked network of siliconized epoxy-bismaleimide using HTPDMS, $\gamma$-aminopropyltriethox-<smiles>CCO[C@H](C[NH3+])CCC1CO1</smiles>

$\gamma$-aminopropyl triethoxysilane

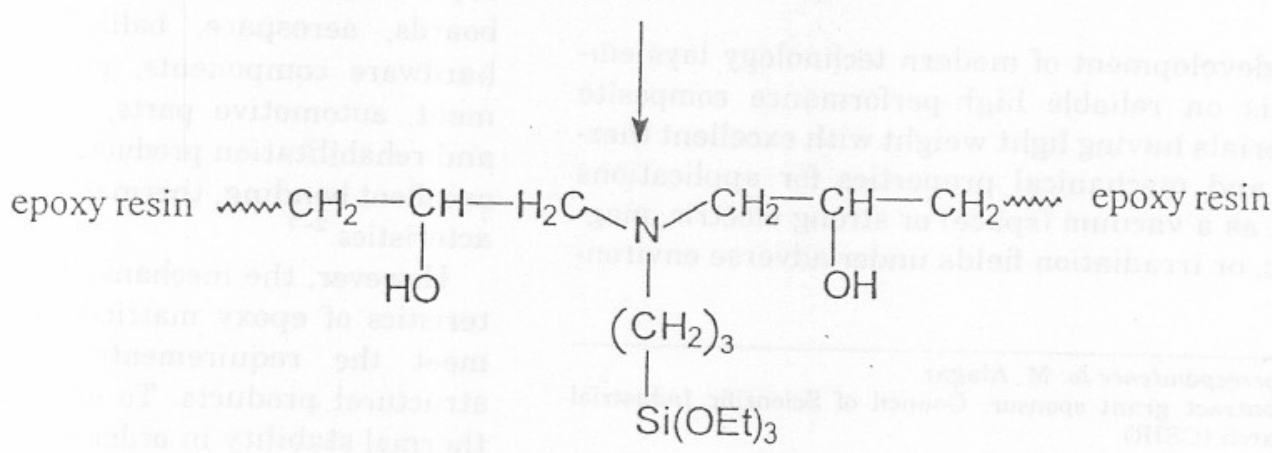

Scheme 1 Preparation of siliconized epoxy resin. 
<smiles>Nc1ccc(Cc2ccc(N)c(Br)c2)cc1</smiles>

maleic anhydride

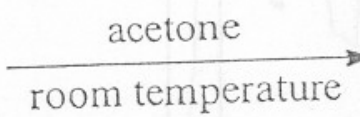<smiles>O=C(O)/C=C\OC(=O)Nc1ccc(Cc2ccc(NC(=O)O)cc2)cc1</smiles>

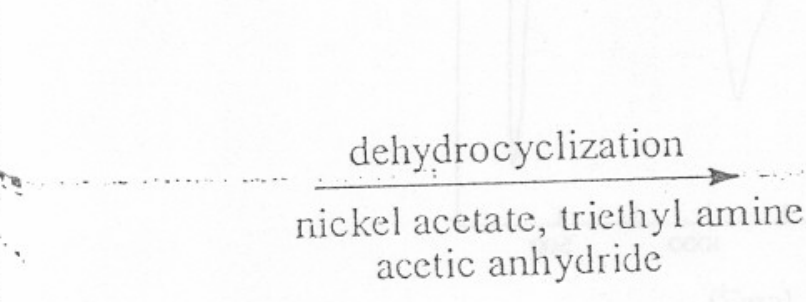<smiles>O=C1C=CC(=O)N1c1ccc(Cc2ccc(N3C(=O)C=CC3=O)cc2)cc1</smiles>

N,N'-bismaleimido-4,4'-diphenyl methane Scheme 2 , Synthesis of BMI.

vsilane ( $\gamma$ APS) as a compatiblizer, dibutyltindilaurate as a catalyst, and bismaleimide.

\section{EXPERIMENTAL}

\section{Materials}

Epoxy resin (diglycidyl ether of bisphenol A, DGEBA) LY556, having an epoxy equivalent of about 180-190 and viscosity of about $10,000 \mathrm{cP}$, and 4,4-diaminodiphenylmethane (DDM) were obtained from Ciba-Geigy Ltd. (Mumbai, India), Bismaleimide [ $N, N^{\prime}$-bismaleimido- $4,4^{\prime}$-diphenylmethane (BMI)] and HTPDMS having a molecular weight of $17,000-18,000$ and a viscosity of $800-900 \mathrm{cP}$ were prepared by the reported procedure. ${ }^{25}$ The HTPDMS used in the present study was synthesized from octamethylcyclotetrasiloxane by the ring-opening polymerization technique. The compatibilizer $\gamma$-APS and the dibutyltindilaurate catalyst were obtained from Union Carbide (Itouston, I'X) and Merck (Darmstadt, Germany), respectively.
Preparation of Siliconized Epoxy Prepolymer

A fixed amount of epoxy resin, a varying : mount of HTPDMS, a stoichimetric amount of $\gamma$-APS (with respect to the ethoxy group), and the dibu. tyltindilaurate catalyst (Table I) were thoroughly mixed at $90^{\circ} \mathrm{C}$ for $10 \mathrm{~min}$ under constant stirring. The product was then degassed to remove ethanol formed during the condensation reaction between $\gamma$-APS and HTPDMS (Scheme 1).

\section{Preparation of BMI}

BMI was prepared according to the reported procedure. $^{25}$ The reaction scheme is given in Scheme 2.

\section{Preparation of Siliconized Epoxy BMI Blend}

The stoichiometric amount of DDM was dissolved into siliconized epoxy resin at $90^{\circ} \mathrm{C}$ under vigror ous stirring. After complete dissolution, a calcu. lated amount of BMI was added. The agitation was continued at $100^{\circ} \mathrm{C}$ until a homogeneous product was obtained. The product was subjected 


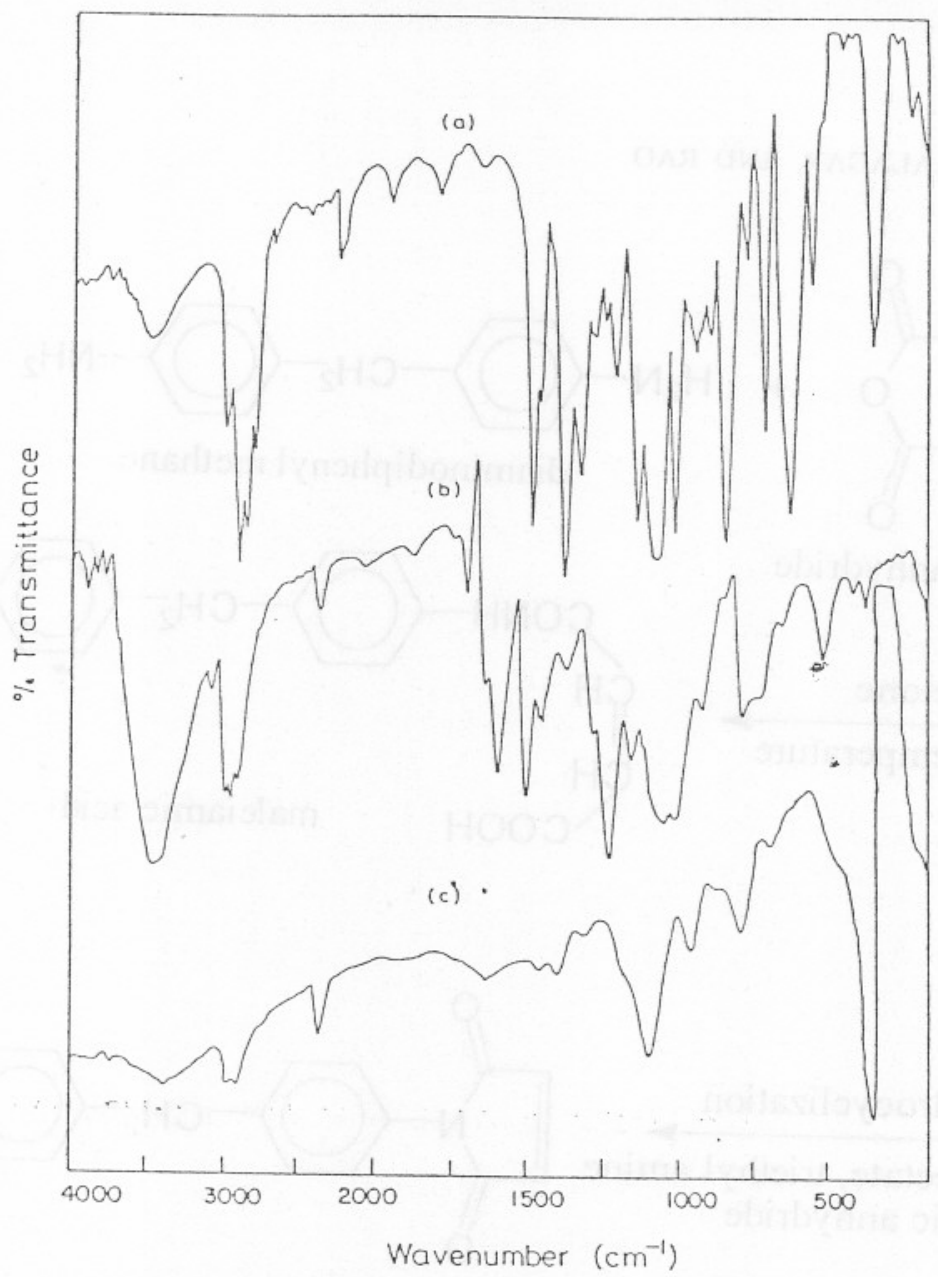

Figure 1 the spectra of (a) unmodified epoxy, (b) $\gamma$-Al's-cured epoxy, and (c) $\gamma$-APS.

to vacuum treatment to remove the trapped air and then cast and cured at $120^{\circ} \mathrm{C}$ for $1 \mathrm{~h}$. The castings were then postcured at $180^{\circ} \mathrm{C}$ for $2 \mathrm{~h}$ and finally removed from the mold and characterized.

Test Niethods

The IR spectra were recorded on a Perkin-Elmer 781 infrared spectrometer and the spectra are presented in Figures 1 and 2. The glass transition temperature $\left(T_{g}\right)$ of the samples was determined using DSC 2910(TA instruments USA) in the tempe: iture range between 50 and $250^{\circ} \mathrm{C}$ at a heatim, rate of $10^{\circ} \mathrm{C} \mathrm{min}-1$. Thermogravimetric analysis (TGA) was carried out using Thermal Analyst 2000 (TA Instruments, USA) at a heating rate of $10^{\circ} \mathrm{C} \mathrm{min}^{-1}$ in an inert atmosphere.

Fractured surfaces were obtained from plain Itrain fracture toughness tested specimens using in Instron testing machine (Model 6025, UK) at a rossh. I speed of $2 \mathrm{~mm} / \mathrm{min}$. Excess material was removed from the other faces of the specimens by a razor blade. The fracture surfaces of the specimens were coated with gold and examined under a scanning electron microscope ISEN I Leica Cambridge, Stercoscan Model 440).

\section{RESULTS AND DISCUSSION}

\section{Spectral Analysis}

The formation of siliconized epoxy network structure proceeds in two steps and was evaluated by IR (Fig. 1): The first step involves the reaction between the epoxide ring of the epoxy resin and the amino group of the $\gamma$-APS and was confirmed by the disappearance of the epoxy band at 91:3 $\mathrm{cm}^{-1}$ and the appearance of the hydroxyl band at $3420 \mathrm{~cm}^{-1}$. Absorption peaks appeared at 2980 and $2850 \mathrm{~cm}^{-1}$ and $1370 \mathrm{~cm}^{-1}$, confirming the presence of $-\mathrm{Si}-\mathrm{O}-\mathrm{CH}_{2} \mathrm{CH}_{33}$ and $-\mathrm{Si}-$ 


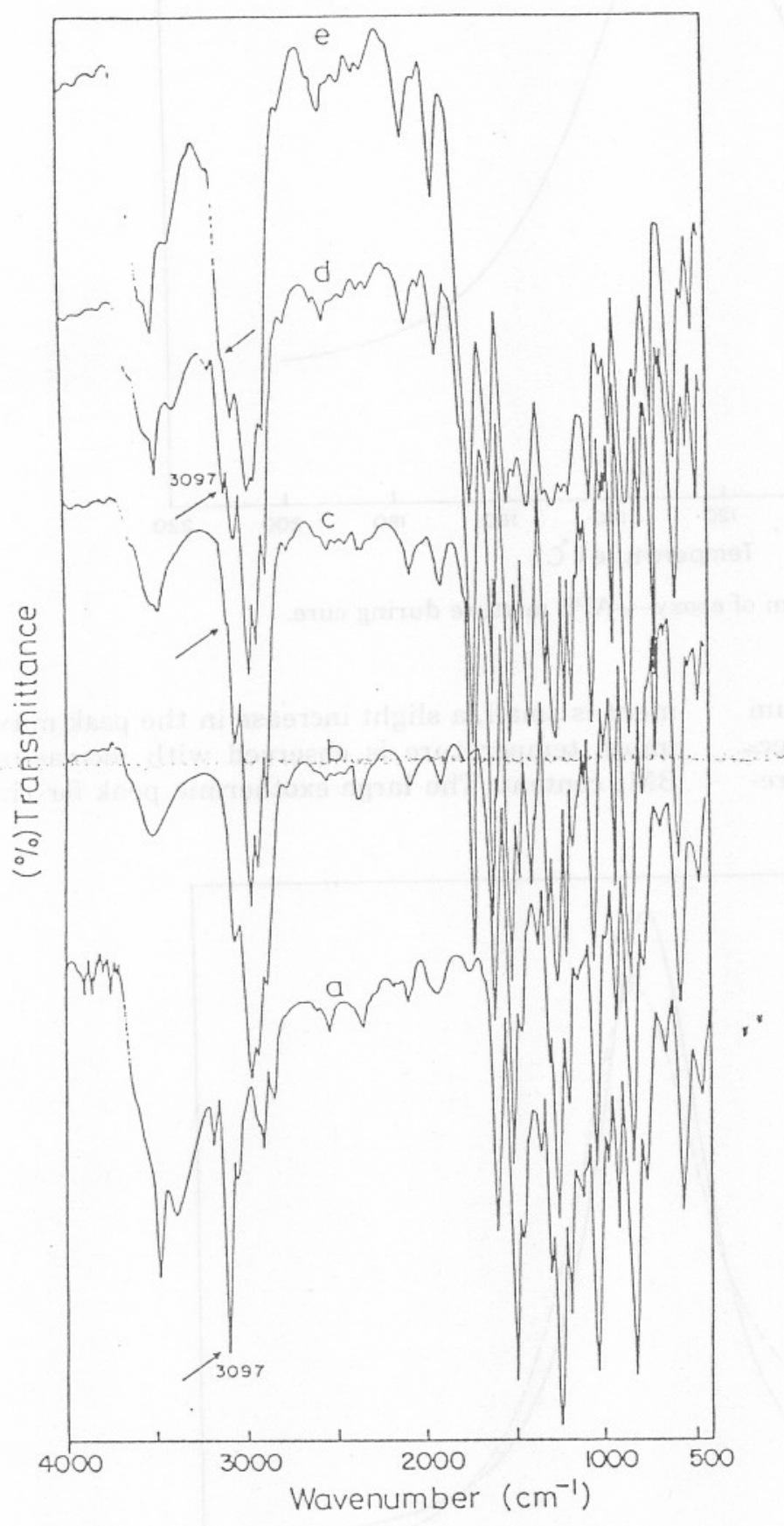

Figure 2 Ife spectra of (a) pure BMI, (b) unmodified epoxy, (c) epoxy/BMI: 100/10, (d) epoxy/BMI: 100/50, and (e) epoxy/BMI: $100 / 50$ after heating $130^{\circ} \mathrm{C}$ for $3 \mathrm{~h}$.

$\left(\mathrm{CH}_{2}\right)_{3}-$, respectively. In the second step, the alkoxy groups present in $\gamma$-APS react with the hydroxyl groups of H'TPDMS.

Figure 2(a,b) represents IR spectra of pure BMI and unmodified epoxy, respectively. The peak at $3097 \mathrm{~cm}^{-1}$ in Figure 2(a) is due to $\mathrm{H}-\mathrm{C}=$ vibration and is widely accepted as a reference to follow the conversion of BMI double bonds.
IR spectra for the mixture of epoxy and $B N^{\circ}$ of varying composition are presented in Figure . . (c) (epoxy/BMI: 100/10) and 2(d) (epoxy/BMI: 100/ 50). The occurrence of the peak at $3098 \mathrm{~cm}^{-1}$ in Figure 2(d) confirms the presence of BMI double bonds in the epoxy mixture, whereas the peak is poorly resolved in Figure 2(c) due to a lower concentration of BMI.

The IR spectrum of Figure 2(e) (epoxy: :II: 100/50) taken after heating the mixture at $1: ; 1^{\prime \prime} \mathrm{C}$ for $3 \mathrm{~h}$ indicates the decrease in the intensity of the $\mathrm{H}-\mathrm{C}=$ vibration peak at $3097 \mathrm{~cm}^{-1}$. This confirms the occurrence of homopolymerization of BMI in the presence of epoxy resin at a lower temperature, whereas the homopolymerization of pure BMI normally occurs at $180^{\circ} \mathrm{C}$ (Fi 6). Hence, epoxy resin aids the homopolymer: lion of BMI at lower temperature.

\section{Cure. Reaction Behavior}

The HTPDMS modification of epoxy resin proceeds in two steps: The first step involve's the reaction between $-\mathrm{NH}_{2}$ groups of $\gamma$-APS : $10 x-$ irane rings of the epoxy resin. From $1.1,1) \mathrm{SC}$ thermogram (Fig. 3), it is evident that the reaction starts at $100^{\circ} \mathrm{C}$ and reaches its peak maximum at $120^{\circ} \mathrm{C}$. Further, the reaction between $-\mathrm{OCH}_{2} \mathrm{CH}_{3}$ groups of $\gamma$-APS and the hydroxyl groups of H'T'PJMS also occurs simulcancously and is accelerated during the degassing process. In the second step, the $-\mathrm{NH}_{2}$ groups : DIDM react with the remaining oxirane rings of the epoxy resin. The epoxy-DDM reaction starts at $120^{\circ} \mathrm{C}$ and reaches its peak maximum at $167^{\prime \prime} \mathrm{C}$ (Fig. 4). The large exotherm obtained for the cp. oxy-DDM system is due to the following reactions: (i) oxirane ring-opening reaction with active amine hydrogens of DDM and (ii) auter talytic reaction of the oxirane ring with pencir.nt hydroxyl groups of epoxy resin and hydroxyl groups formed during reaction (i) (Fig. 5). The exolherm obtained for the reaction of epoxy resin with a mixture of $\gamma$-APS and DDM shows unimodal be. havior (Fig. 4). The exotherm starts at $70^{\circ} \mathrm{C}$ and reaches its peak maximum at $165^{\circ} \mathrm{C}$, surgresting that the reaction proceeds in a hommencous path.

DSC thermograms of the BMML-modified epoxy resin containing 5,10 , and $15 \%$ BMI-incorporated epoxy systems are presented in Figure 6. BMI incorporated epoxy systems show unimodal renction exotherm due to its lower concentration. In the BMI-incorporated systems, the reaction com 


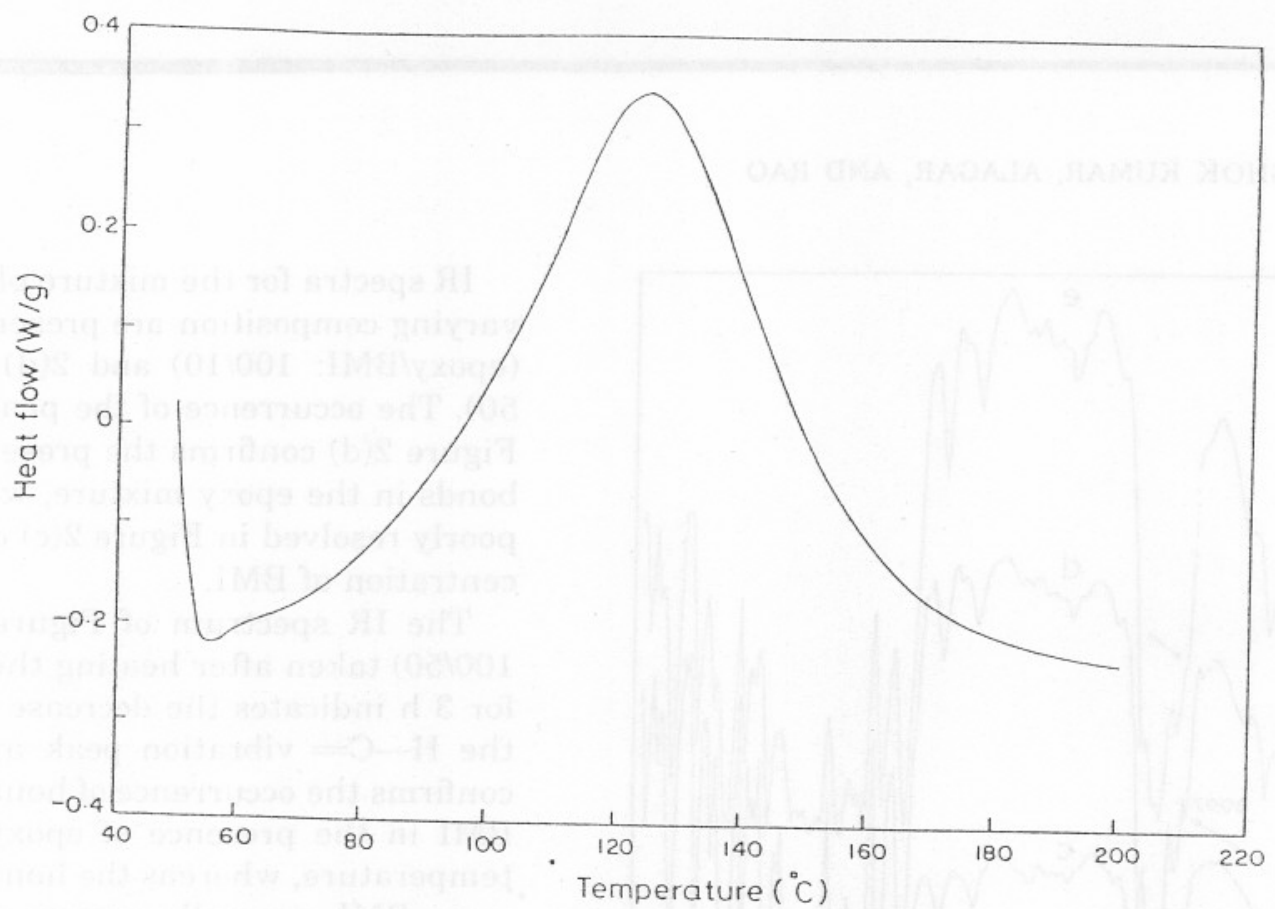

Figure 3 DSC thermogram of epoxy- $\gamma$-APS mixture during cure.

mences at $120^{\circ} \mathrm{C}$ and reaches the peak maximum at 169,172 , and $175^{\circ} \mathrm{C}$ for 5,10 , and $15 \%$ respec= tively. Since, the concentration of the BMI incre- ment is small, a slight increase in the peak maximum temperature is observed with increasing BMI content. The large exothermic peak for the

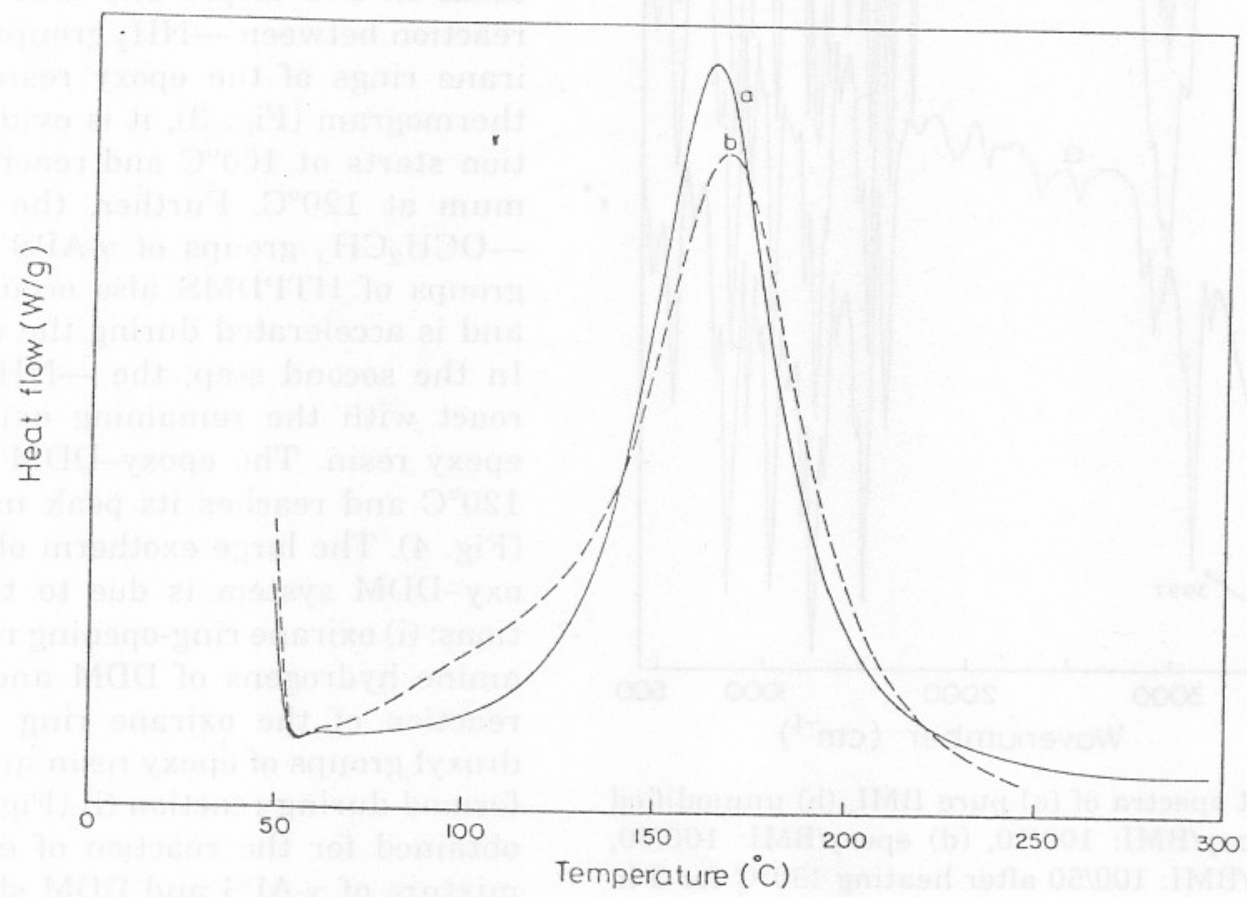

Figure 4 DSC thermograms of (a) epoxy-DDM and (b) mixture of epoxy-DI)M- $\gamma$-APS systems during cure. 


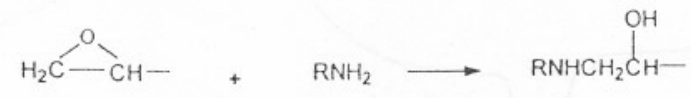

(ii)
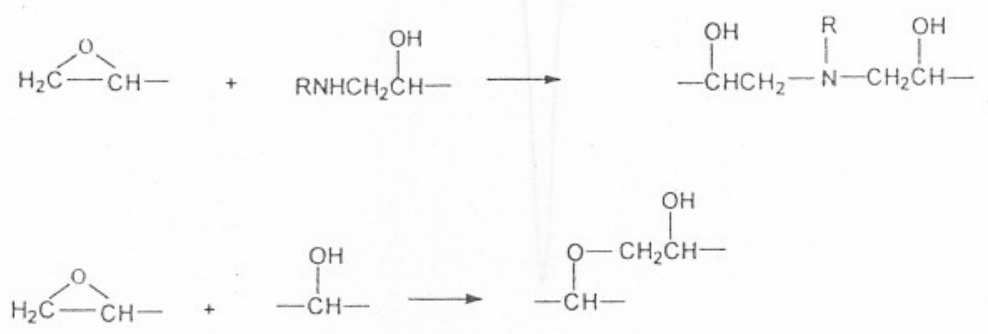

(iii)

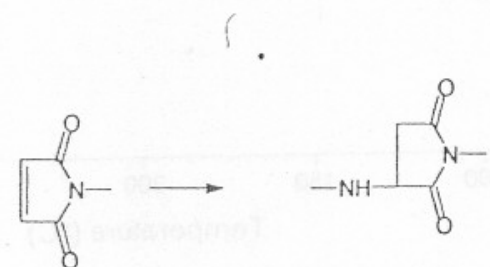

(iv)<smiles>CN1C(=O)C=CC1=O</smiles><smiles>CC1C(=O)N(C)C(=O)C1C1C(=O)N(C)C(=O)C1C</smiles>

Figure 5 Reactions involved during the curing process of BMI-modified epoxy systems.

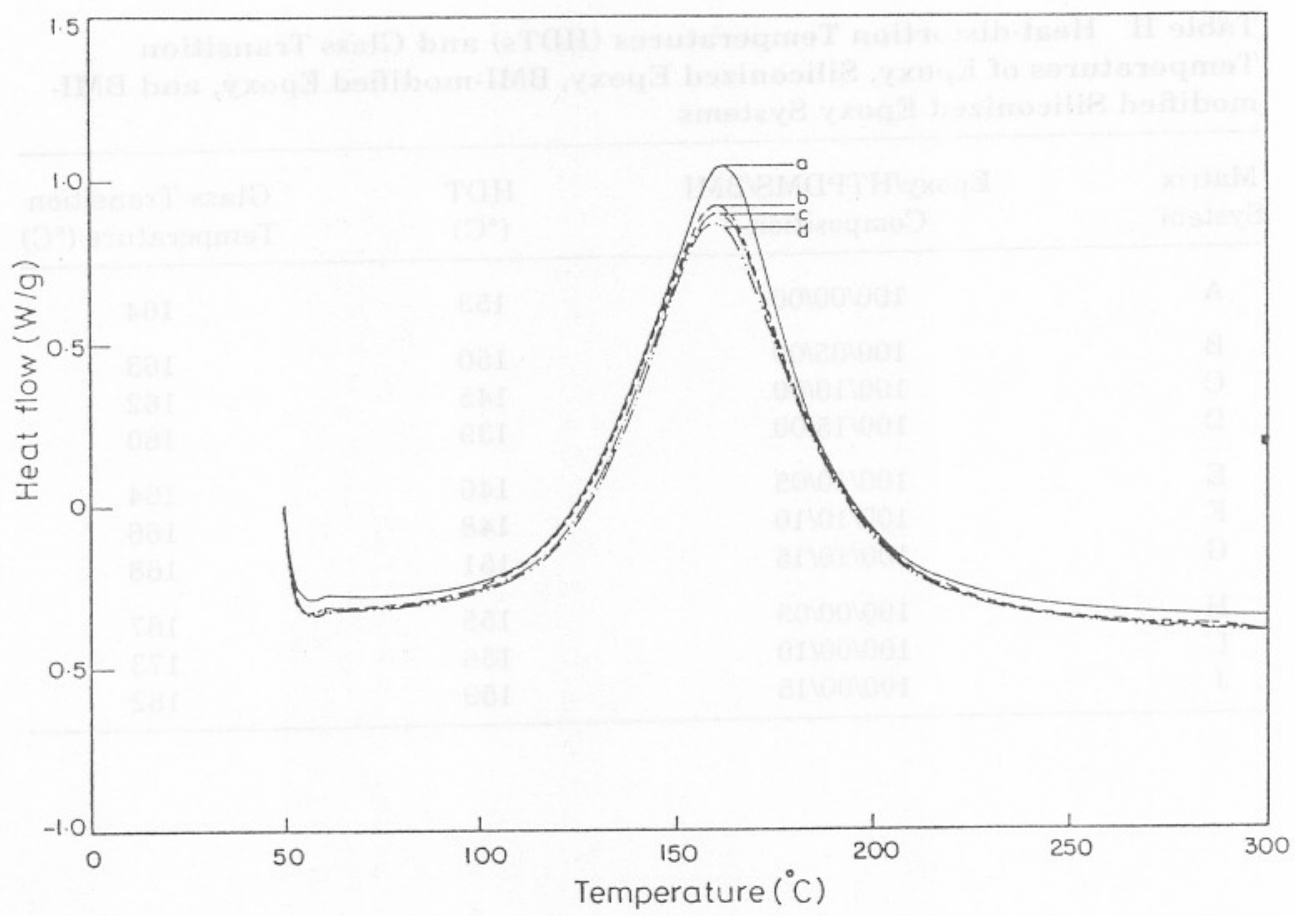

Figure 6 DSC thermograms of epoxy-BMI systems during cure: (a) epoxy-DDM; (b) epoxy-DDM-5\% BMI; (c) epoxy-DDM-10\% BMI; (d) epoxy-DDM-15\% BMI. 


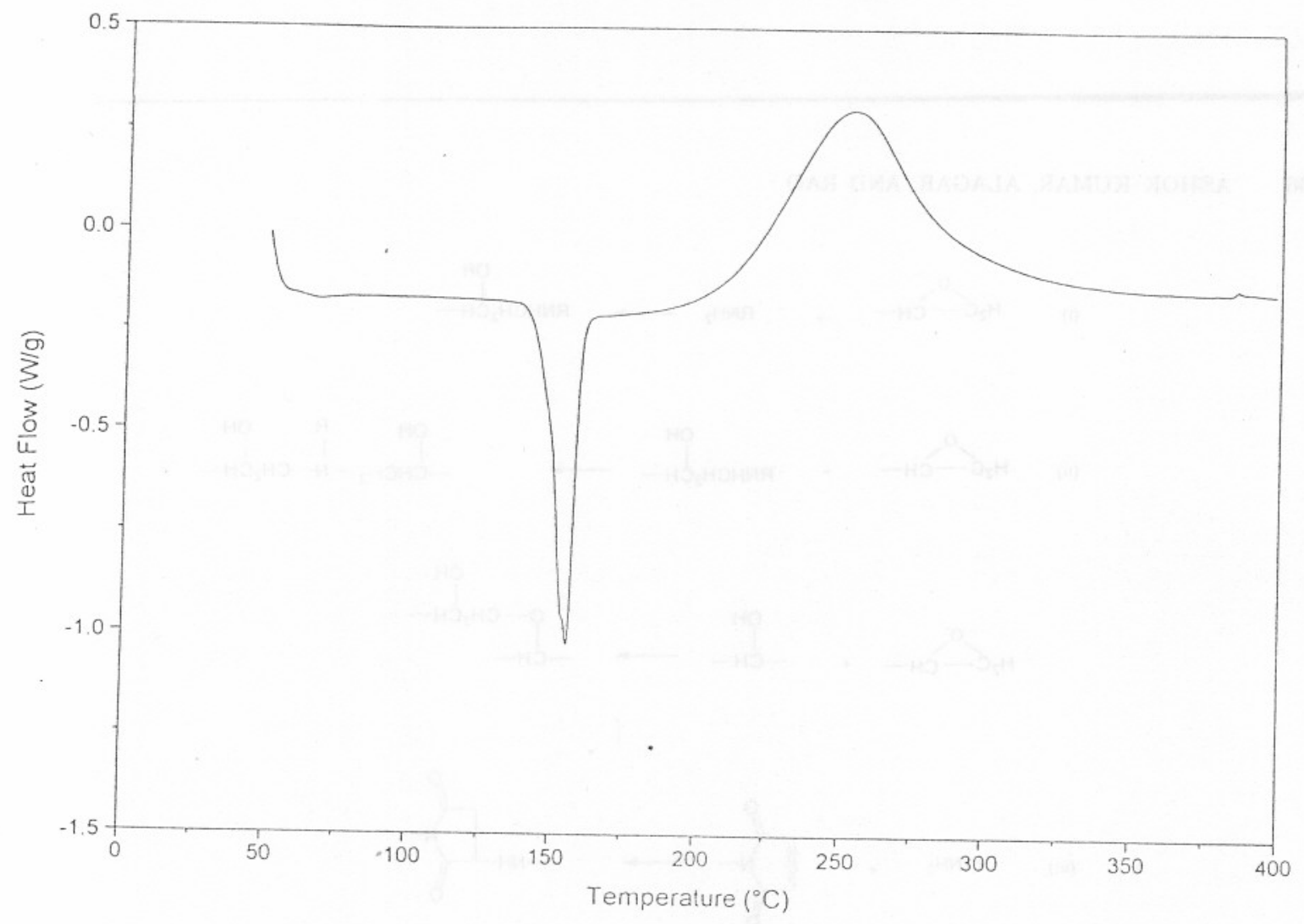

- $\quad$ Figure 7 DSC thermograms of BMI during cure.

Table II Heat-distortion Temperatures (HDTs) and Glass Transition Temperatures of Epoxy, Siliconized Epoxy, BMI-modified Epoxy, and BMImodified Siliconized Epoxy Systems

\begin{tabular}{cccc}
$\begin{array}{c}\text { Matrix } \\
\text { System }\end{array}$ & $\begin{array}{c}\text { Epoxy/HTPDMS/BMI } \\
\text { Composition }\end{array}$ & $\begin{array}{c}\text { HDT } \\
\left({ }^{\circ} \mathrm{C}\right)\end{array}$ & $\begin{array}{c}\text { Glass Transition } \\
\text { Temperature }\left({ }^{\circ} \mathrm{C}\right)\end{array}$ \\
\hline $\mathrm{A}$ & $100 / 00 / 00$ & 153 & 164 \\
$\mathrm{~B}$ & $100 / 05 / 00$ & 150 & 163 \\
$\mathrm{C}$ & $100 / 10 / 00$ & 145 & 162 \\
$\mathrm{D}$ & $100 / 15 / 00$ & 139 & 160 \\
$\mathrm{E}$ & $100 / 10 / 05$ & 146 & 164 \\
$\mathrm{~F}$ & $100 / 10 / 10$ & 148 & 166 \\
$\mathrm{G}$ & $100 / 10 / 15$ & 151 & 168 \\
$\mathrm{H}$ & $100 / 00 / 05$ & 155 & 173 \\
$\mathrm{I}$ & $100 / 00 / 10$ & 156 & 182 \\
$\mathrm{~J}$ & $100 / 00 / 15$ & 159 & \\
\hline
\end{tabular}




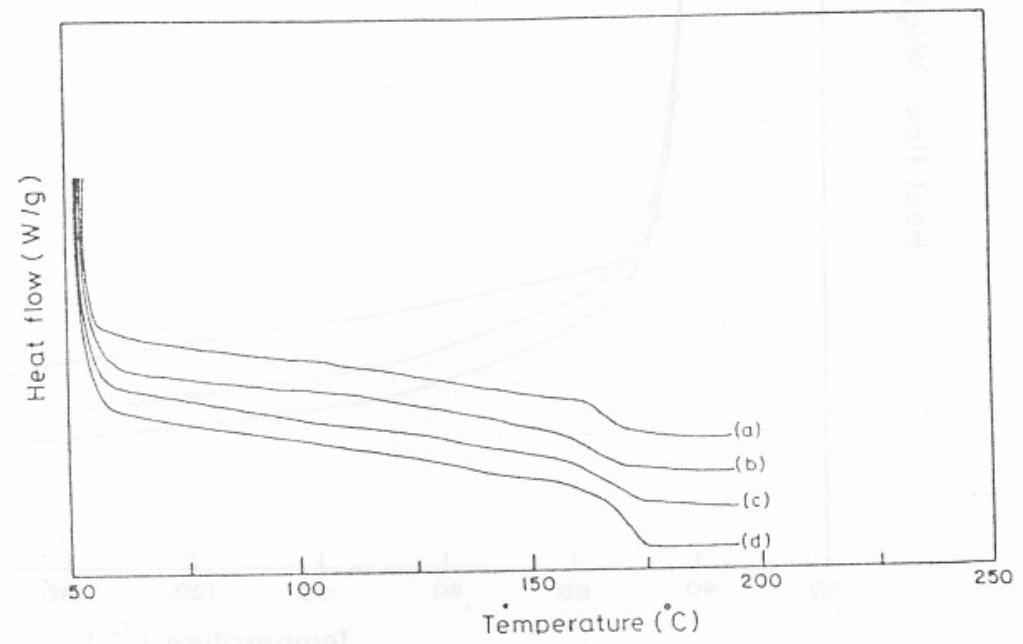

Figure 8 DSC traces of epoxy and siliconized epoxy systems: (a) unmodified epoxy and (b) $5 \%$, (c) $10 \%$, and (d) $15 \%$ HTPDMS-modified epoxy systems.

BMI-incorporated system is due to the following reactions: (iii) addition reaction of $-\mathrm{NH}_{2}$ groups of DDMI with double bonds of BMI (Michael addition) and (iv, BMI homopolymerization reaction in addition to reactions (i) and (ii) (Fig. 5). It is observed that the homopolymerization of the BMI reaction starts at $180^{\circ} \mathrm{C}$ (Fig. 7). Earlier, it was reported that reaction (iv) is the least possible due to the requirement of higher activation encrgy to initiate the homopolymerization of BMI. However, according to Musto et al., ${ }^{22}$ in the pr. ence of epoxy resin, the same reaction (homopolynerization of BMI) starts at about $120-140^{\circ} \mathrm{C}$, because of the formation of zwitterion adduct be-

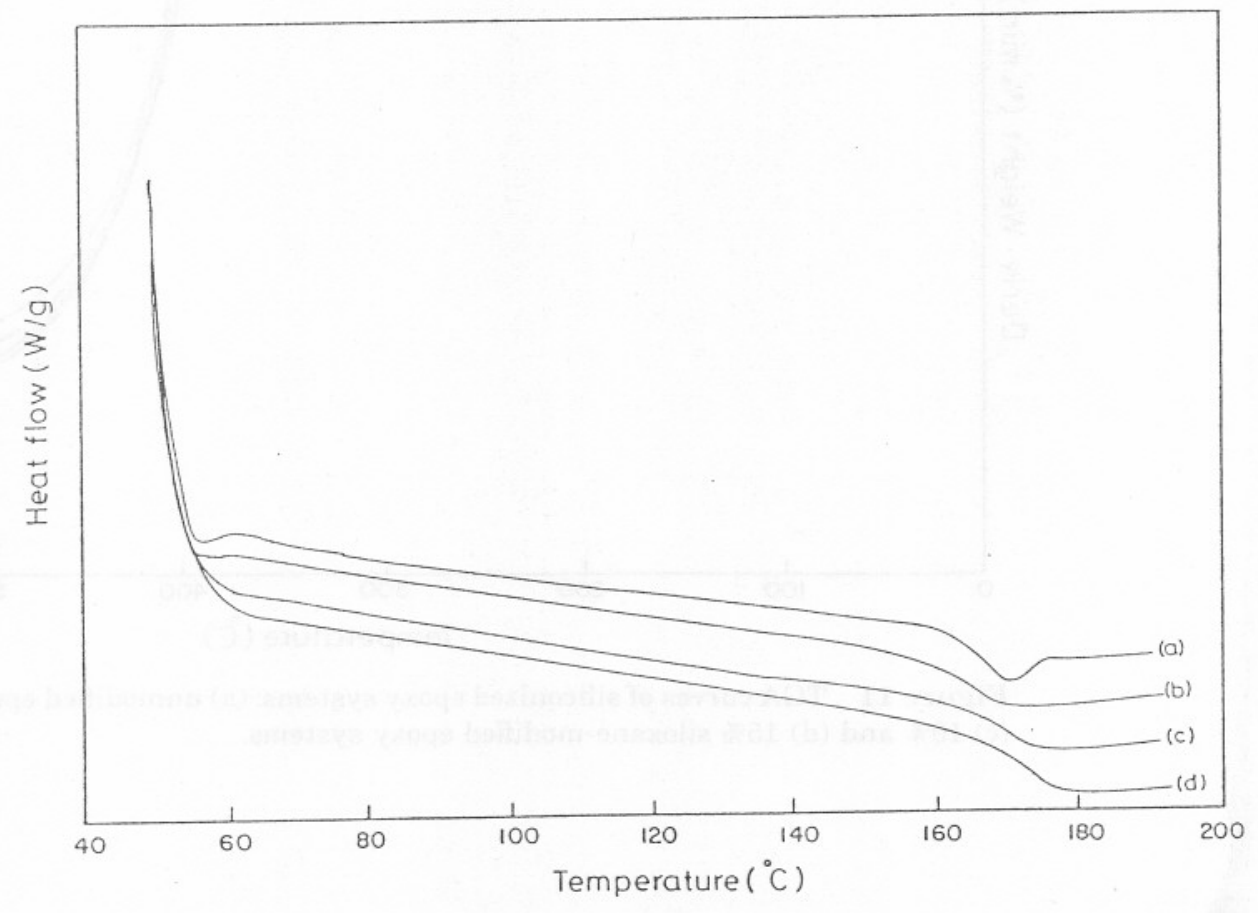

Figure 9 DSC traces of BMI-modified epoxy systems: (a) unmodified epoxy and (b) $5 \%$, (c) $10 \%$ and (d) $15 \%$ BMI-modified epoxy systems 


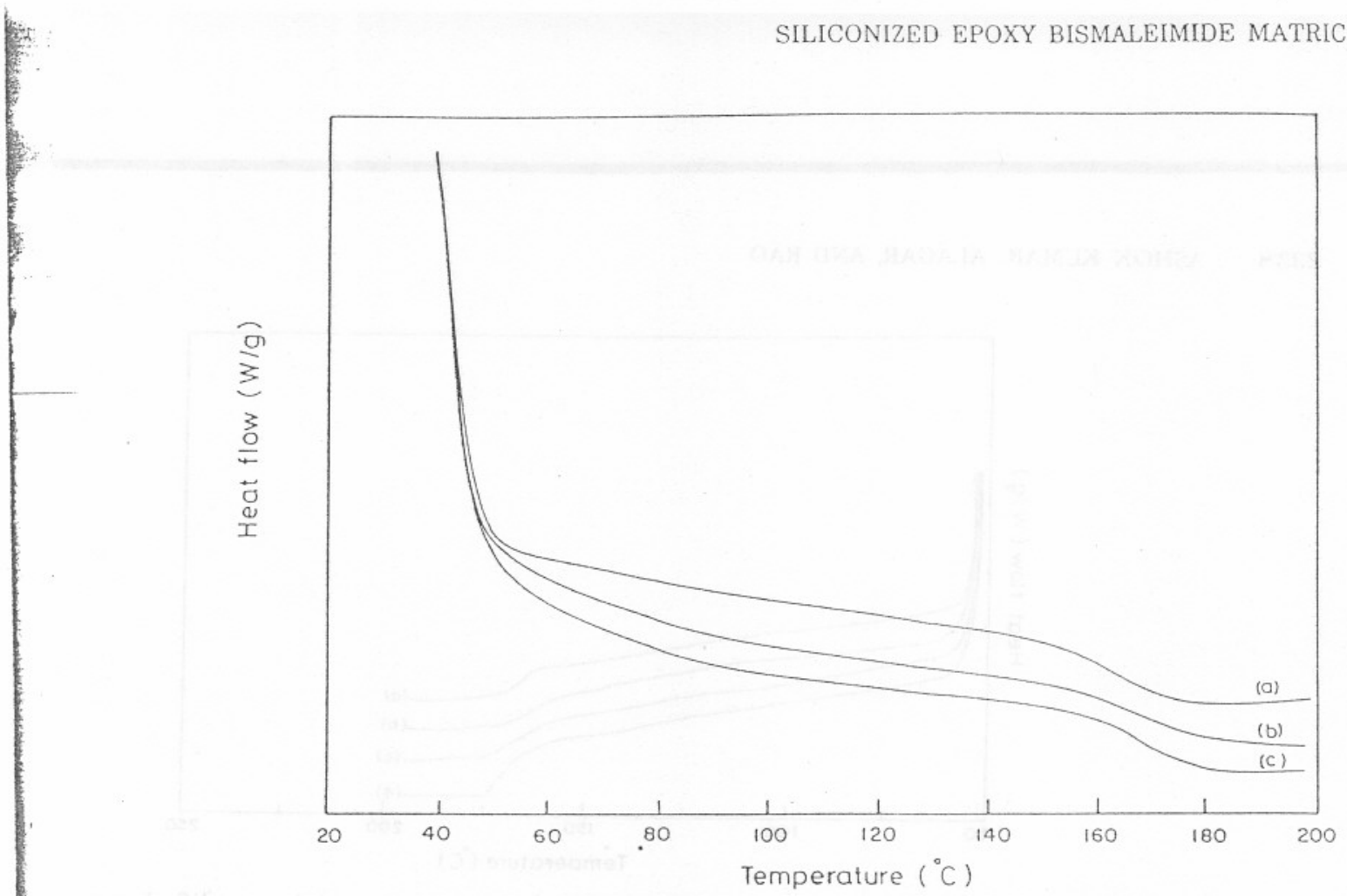

Figure 10 DSC traces of $10 \%$ siliconized epoxy/BMI systems: (a) $5 \%$, (b) $10 \%$, and (c) 15\% BMI-modified 10\% siliconized epoxy systems.

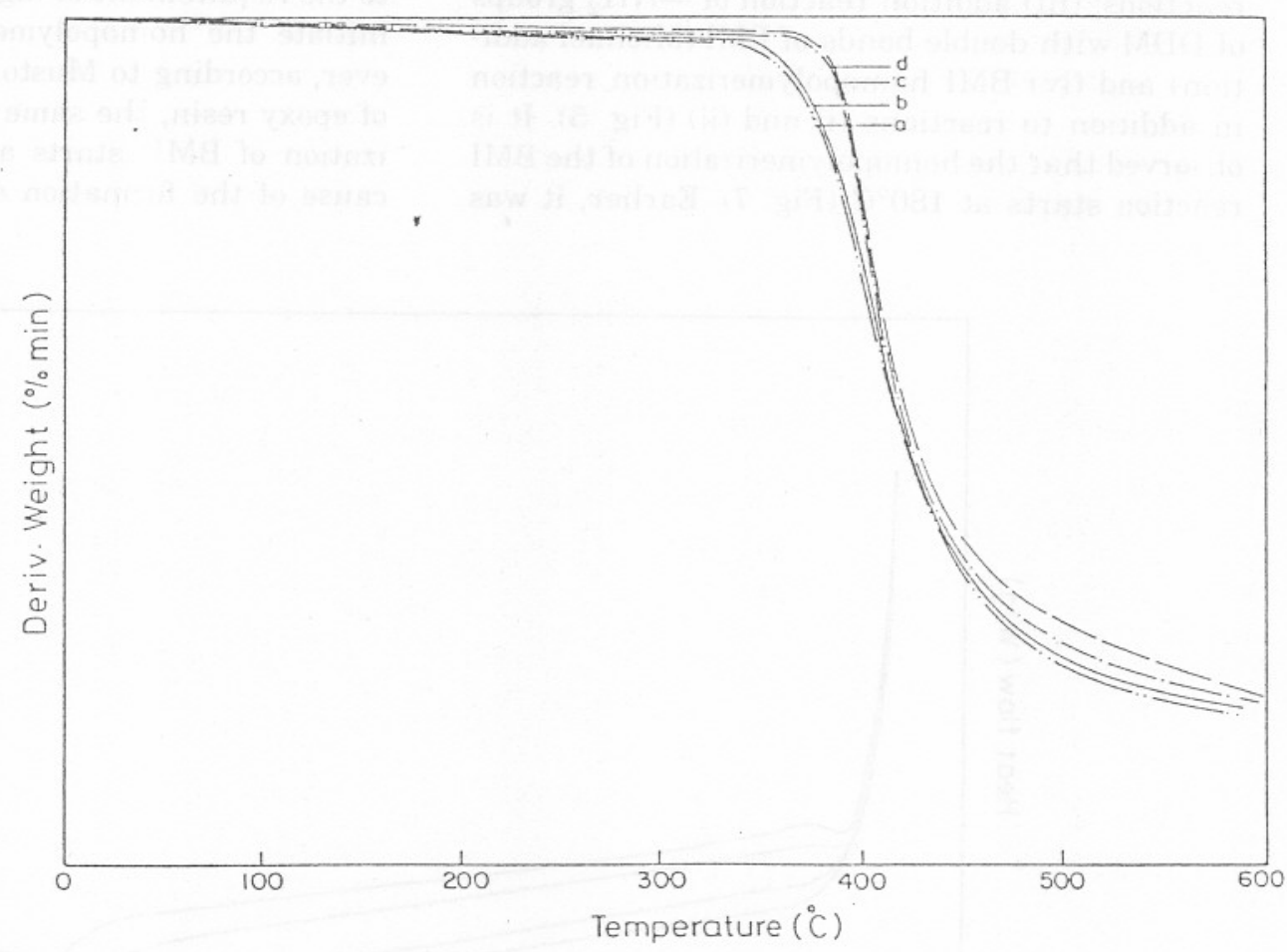

Figure 11 TGA curves of siliconized epoxy systems: (a) unmodified epoxy, and (b) $5 \%$, (c) $10 \%$ and (d) $15 \%$ siloxane-modified epoxy systems. 


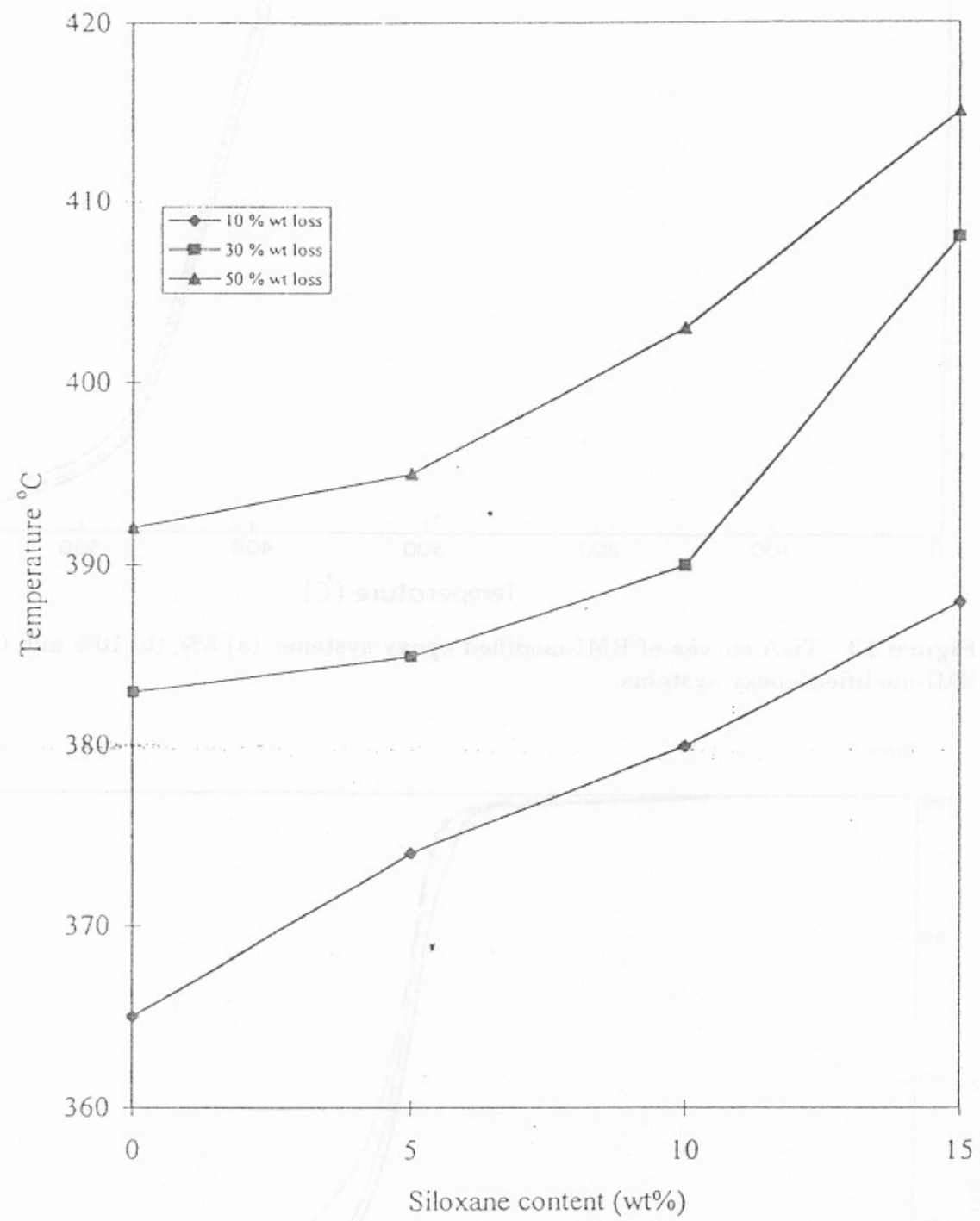

Figure 12 Effect of siloxane content on percentage weight loss.

tween the oxirane ring and the double bond of BMI. The slight increase in the peak maximum temperature with increasing BMI concentration confirms the observation made by Musto et al. ${ }^{22}$

\section{Glass Transition Temperature}

The glass transition temperatures of the matrix systems are presented in Table II. The glass transition temperature obtained for the epoxy-DDM system is $165^{\circ} \mathrm{C}$. Incorporation of HTPDMS into the epoxy resin had no significant effect on the $T_{g}$ (Table II and Fig. 8). However, a slight decreasing trend is observed with increasing HTPDMS concentration. The $T_{g}$ for 5,10 , and 15\% HTPDMSmodified systems are 163,162 , and $160^{\circ} \mathrm{C}$, respec- tively. By the incorporation of BMI into ! ...th epoxy and siliconized epoxy systems, the silue of the $T_{g}$ increases with increasing BMI concentration (Figs. 9 and 10). The increase in the values of $T_{g}$ for both BMI-modified epoxy and BMI-modified siliconized epoxy systems are due to homopolymerization of BMI rather than Michael addition. Michael addition reaction leads to the formation of thermally weak amine linkise and ultimately reduces the crosslinking density due to chain extension, ${ }^{26}$ whereas BMI homopolymerization leads to the thermally stable $\mathrm{C}-\mathrm{C}$ link. age. The increase in $T_{g}$ confirms that the BMI homopolymerization reaction is predominant over Michael addition. Further, it lends support to the 


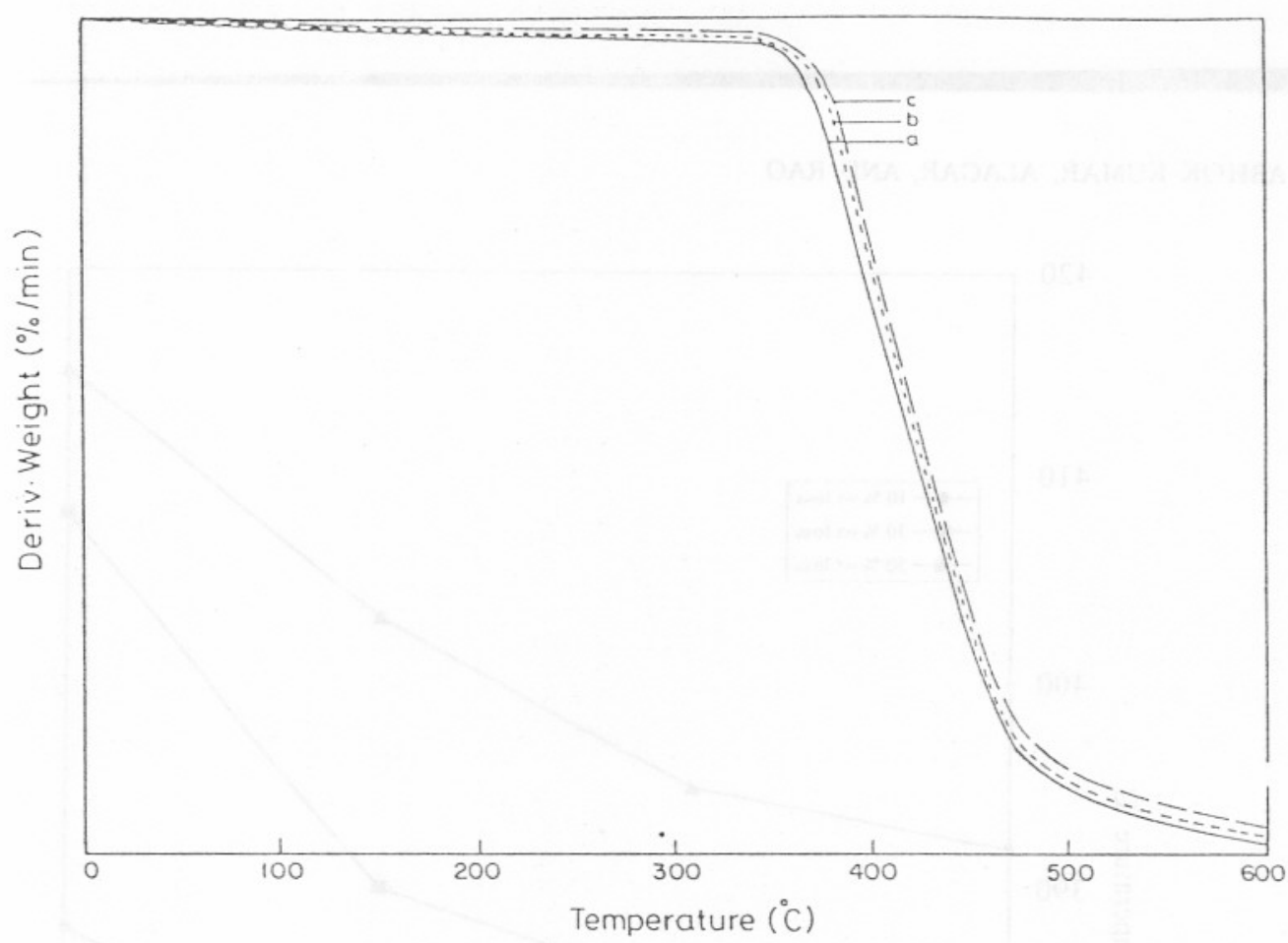

Figure 13 TGA curves of BMI-modified epoxy systems: (a) $5 \%$, (b) $10 \%$ and (c) $15 \%$ BMI-modified epoxy systems.

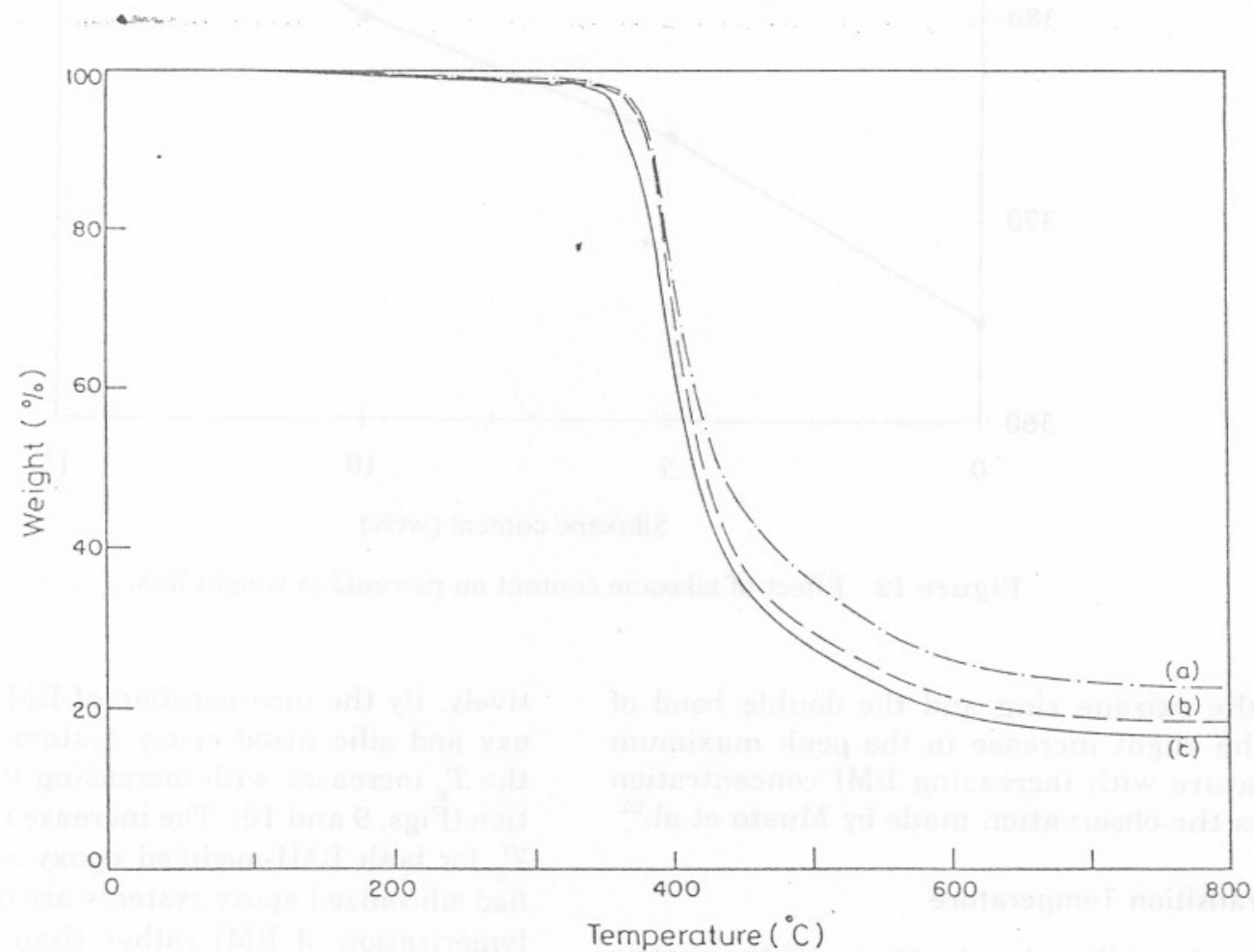

Figure 14 TGA curves of $10 \%$ siliconized epoxy/BMI systems: (a) $5 \%$, (b) $10 \%$, and (c) $15 \%$ BMI modified $10 \%$ siliconized epoxy systems. 


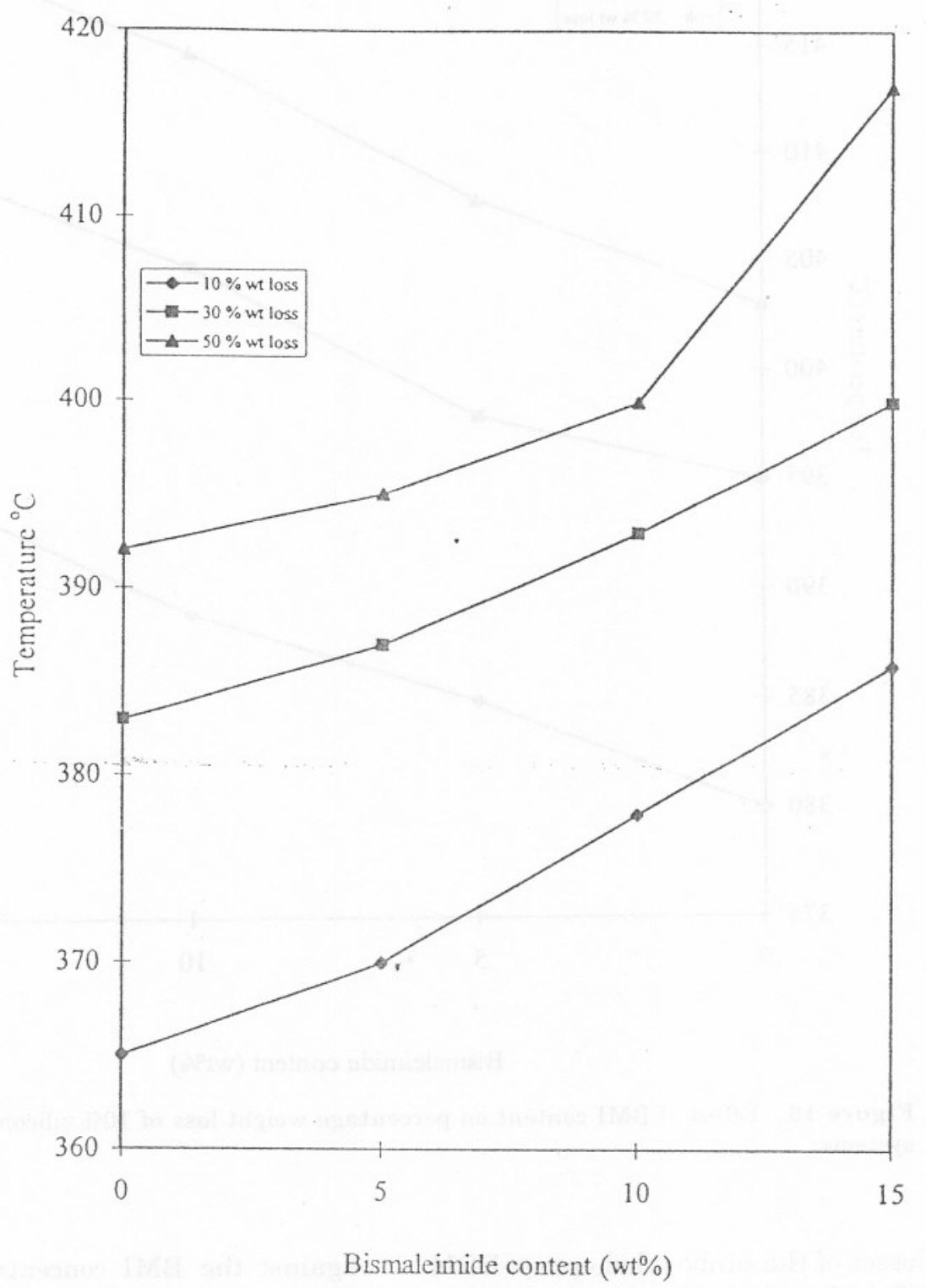

Figure 15 Effect of BMI content on percentage weight loss.

earlier observation made by Musto et al. that, in the presence of epoxy resin, the BMI homopolymerization reaction starts even at $120-140^{\circ} \mathrm{C} .{ }^{22}$ The single $T_{g}$ value obtained for the BMI-modified systems (Figs. 9 and 10 and Table II) further confirms the presence of intercrosslinked network structure.

\section{Thermogravimetric Analysis}

Thermogravimety is the most important method to assess the thermal stability of polymeric materials. Incorporation of siloxane into epoxy resin improves the thermal stability and enhances the degradation temperature according to its percent. age concentration (Fig. 11). The presence of the siloxane skeleton in the system delays the degradation and a high amount of thermal energy is required to attain the same weight lowis when compared with that of an unmodified epoxy system. The delay in degradation by the siloxane moiety may be attributed to the stability of the inorganic nature of the siloxane structure, which. may stabilize the epoxy resin from the heat. For example, the temperature required for 10,30 , and 


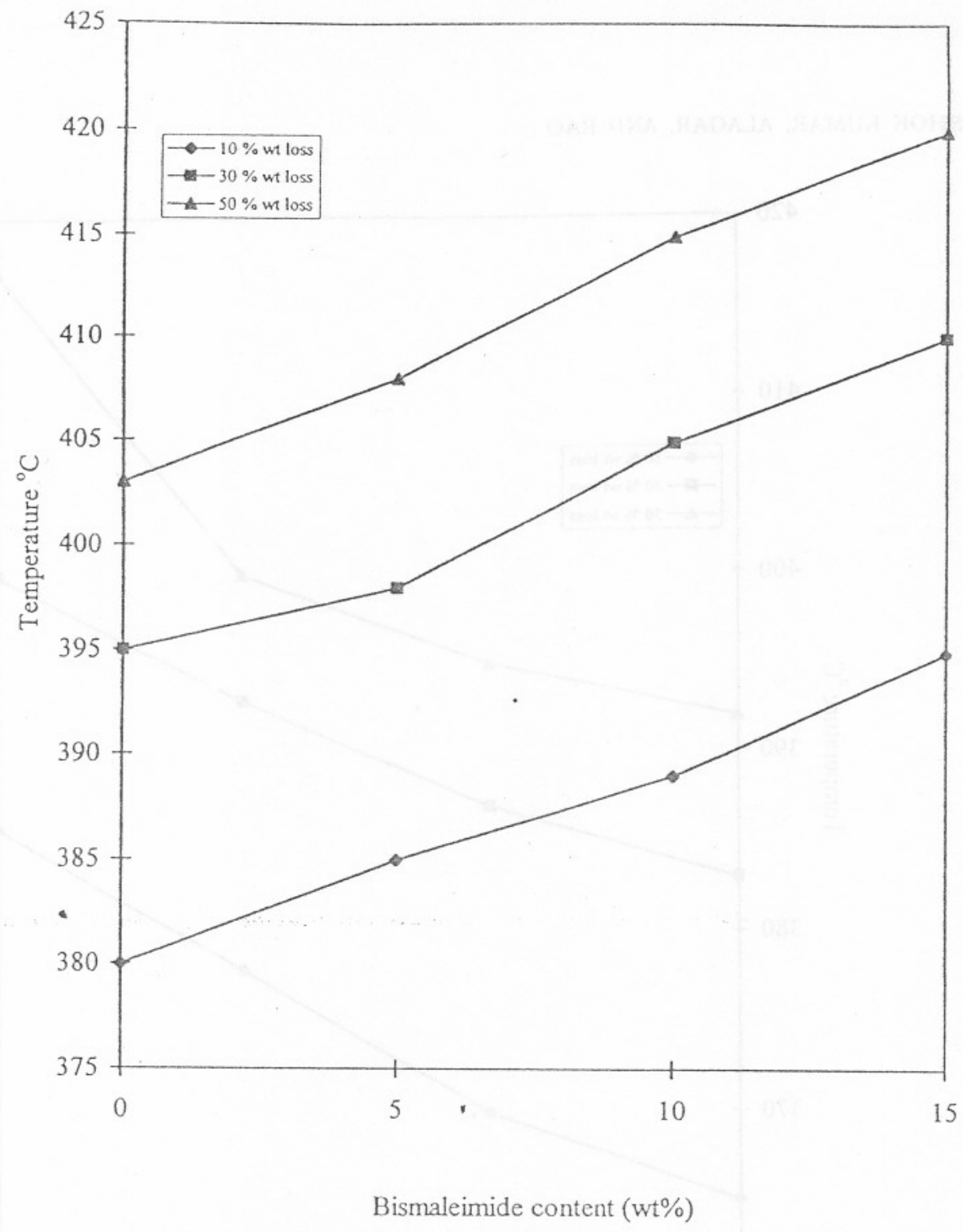

Figure 16 Effect of BMI content on percentage weight loss of $10 \%$ siliconized epoxy systems.

$50 \%$ weight losses of the unmodified epoxy-DDM system are 365,383 , and $392^{\circ} \mathrm{C}$, whereas the temperatures required to attain the same weight losses $\mathrm{for}$ the 15\% HTPDMS-modified system increas $\cdots$ to 388,408 , and $415^{\circ} \mathrm{C}$, respectively (Fig. 12). A similar trend is observed for 5 and $10 \%$ HTPDMS-modified epoxy systems.

From Figures 13 and 14, it is observed that the thermal degradation temperature of both BMImodified epoxy and BMI-modified siliconized epoxy systems increases with increasing BMI content. ".e plot of the degradation temperature against the BMI concentration is presented in Figure 15. From Figure 15, it is evident that the degradation temperature increases with increasing BMI concentration as observed in the case of HTPDMS-modified systems. The delay in degradation is mainly due to the thermally stable aromatic-heterocyclic structure of BMI and the formation of intercrosslinking network with $\in \mathrm{p}$ oxy resin. The thermal stability of the BMImodified siliconized epoxy system is slightly higher than that of the BMI-modified epoxy and HTPDMS-modified epoxy systems (Fig. 16). For 


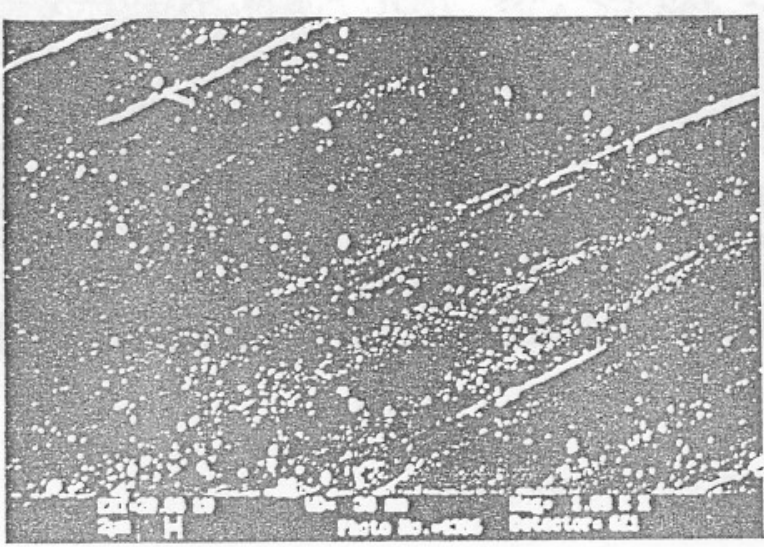

(a)

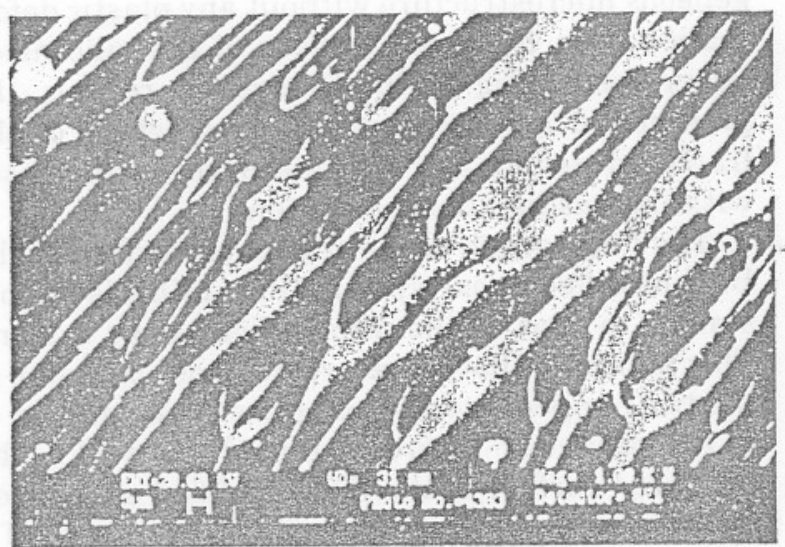

(c)

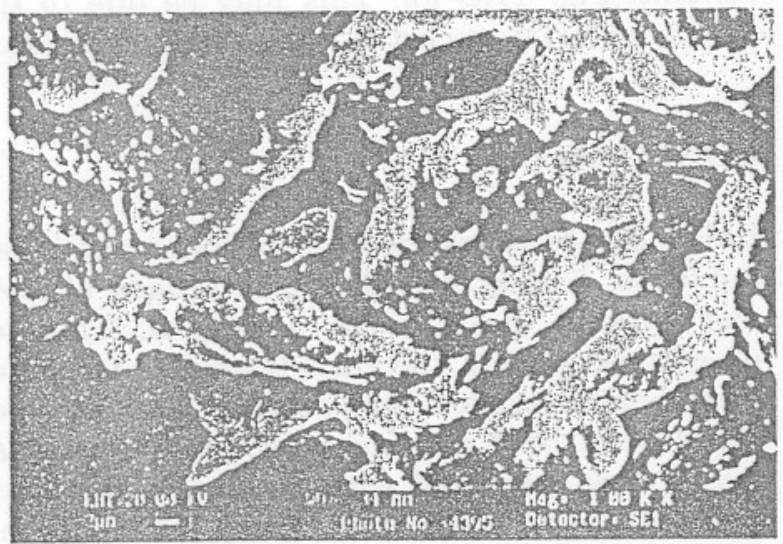

(e)

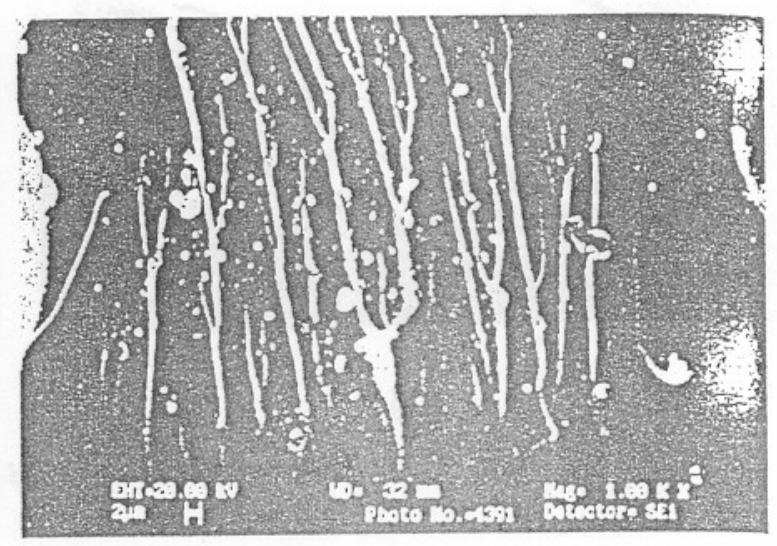

(b)

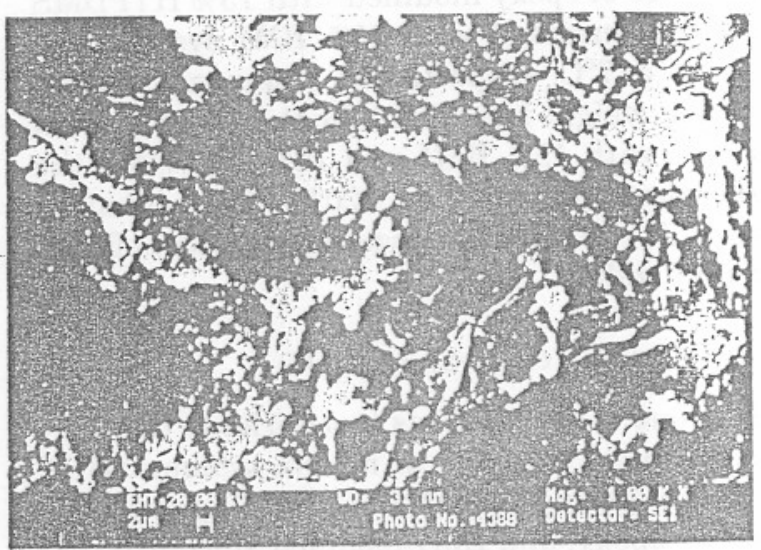

(d)

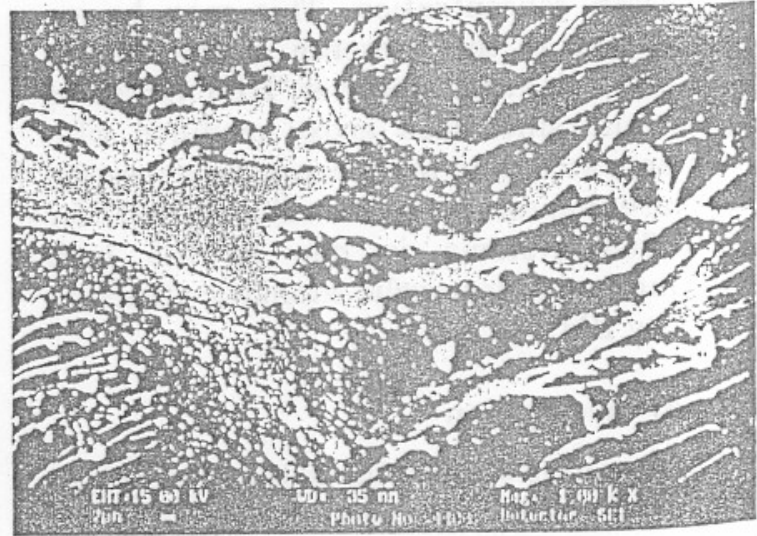

$(f)$

Figure 17 SEM micrographs of fracture surfaces of (a) unmodified epoxy, (b) $5 \%$, (c) $10 \%$, and (d) $15 \%$ siloxane-modified epoxy; (e) $5 \%$, (f) $10 \%$, and (g) $15 \%$ BMI-modified $10 \%$ siliconized epoxy, and (h) 10\% BMI-modified epoxy systems. 


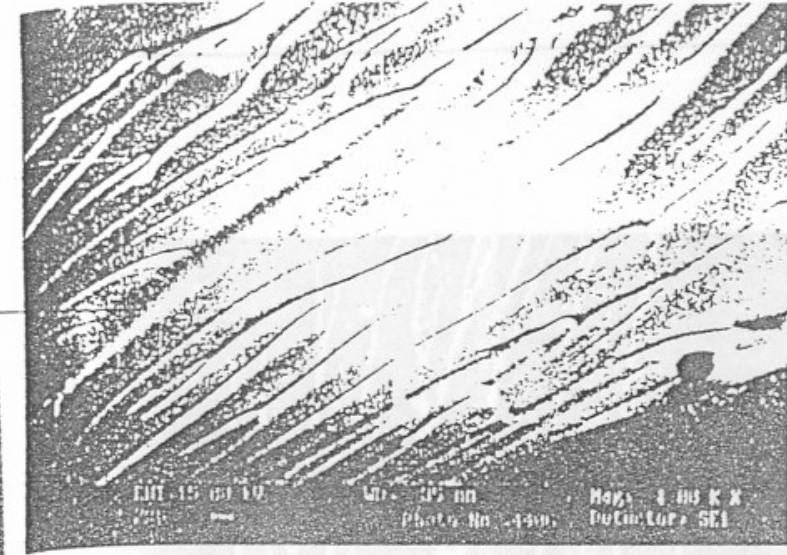

(g)

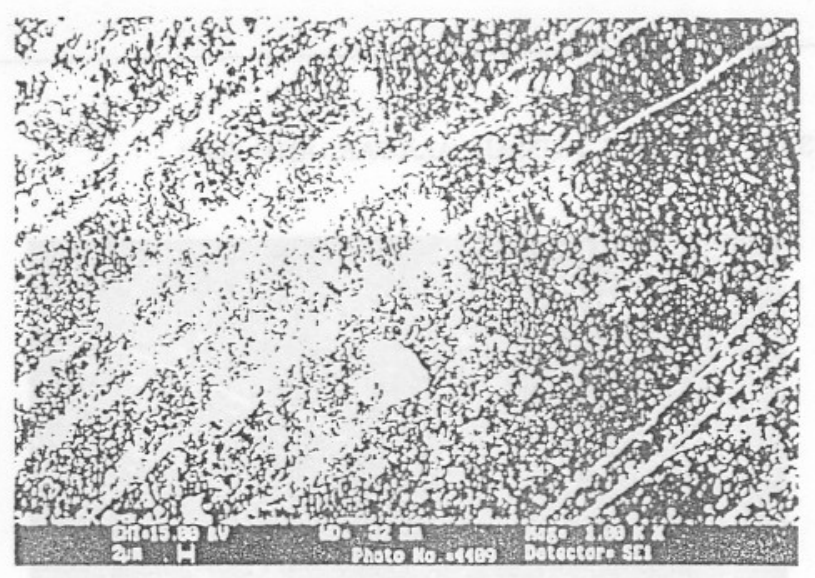

( $h$ )

Figure 17 (Continued from the previous page)

example, the temperature required for a $50 \%$ weight loss of epoxy modified with $15 \%$ HTPDMS and enoxy modified with $15 \%$ BMI systems are 415 and $417^{\circ} \mathrm{C}$, respectively, whereas to attain the same weight loss $(50 \%)$ for the epoxy system modified with $15 \%$ BMI and $10 \%$ HTPDMS the temperature increases to $420^{\circ} \mathrm{C}$. This enhancement is due mainly to a synergistic effect.of BMI and HTPDMS.

Heat-r.:sortion Temperature (HDT)

HDT is one of the methods to determine the thermomechanical behavior of matrix systems. HDT values for epoxy, HTPDMS-modified epoxy, BMImodified epoxy, and BMI-modified siliconized epoxy systems are presented in Table II. From Table II, it is evident that HDT decreases with increasing H'PMS concentration. This may be explaines: as due to the presence of the flexible - $\mathrm{Si}-\mathrm{O}-\mathrm{Si}$ - linkage. However, HDT increases for epoxy and siliconized epoxy modified with BMI systems according to its percentage incorporation. The enhancement in the values of HDT for BMI-modified systems is due to the high crosslinking and heterocyclic-aromatic structure impart، : by BMI.

\section{Microscopy Investigation}

The SEM was used to investigate the morphology f unmodified epoxy, siliconized epoxy, BMI-modfied epoxy, and BMI-modified siliconized epoxy lystems (Fig. 17). The SEM micrograph of the facturc: : :urface of the unmodified epoxy system
[Fig. 17(a)] reveals a smooth, glassy, and homogeneous microstructure without any plastic deformation. The fractured surface of the siliconized epoxy resin [Fig. 17(b-d)] system reveals the presence of a heterogeneous morphology of the fractured surface and the heterogeneity increases with increasing siloxane content.

The micrograph of the fractured surface of the BMI-modified epoxy system [Fig. 17(h)] is almost similar to that of the unmodified epoxy system. This indicates that there are no phase domains of the two components and suggests the formation of a homogeneous intercrosslinked network. The fractured surface of the BMI-modified siliconized epoxy system, however, reveals the presence of a heterogeneous morphology and also a smooth fracture surface is observed with increasing BMI content [Fig. 17(e-g)]. This may be due to the brittle behavior imparted by the BMI skeleton.

\section{CONCLUSIONS}

BMI-modified siliconized epoxy intercrosslinked networks, having varied concentrations of BMI and siloxane units, were developed. Thermal properties, namely, the glass transition temperature, heat-distortion temperature, and thermal stability, of BMI-modified siliconized epoxy matrices were compared with those of unmodified epoxy systems; siliconized epoxy systems, and BMI-modified epoxy systems. HTPDMS modification imparts higher thermal stability to the epoxy systems without significantly improving the glass 
transition and heat-distortion temperatures. However, BMI-modified siliconized epoxy systems $\epsilon$ xhibit intermediate behavior between the above t:wo extremes, in addition to improvement in truphomess behavior, which is the prime objective of epoxy modification with flexible siloxane units and rigid BMI units.

Further, the single glass transition values obtained for the siliconized epoxy systems and BMImodified siliconized epoxy systems indicate the presence of an intercrosslinking network. The morphology from the SEM micrograph indicates that the silicone modification gives a distinct heterogeneous morphology, whereas BMI modification has a homogeneous morphology.

The authors thank Dr. T. S. Prahlad, Director, National Aerospace Laboratories, Bangalore, India, for providing the research facilities. The authors also acknowledge Ms. Vanaja and Ms. Sandhya Rao for their valuable assistance in material characterization and the Council of Scientific Industrial Research (CSIR) for financial support.

\section{REFERENCES}

1. Gouri, C.; Reghunadhan Nair, C. P.; Ramaswamy, R. J Appl Polym Sci 1999, 73, 695-705.

2. Akutsu; F.; Inoki; M.; Daicho, N.; Kasashima, Y.; Shiraishi; N.; Marushima, K. J Appl Polym Sci 1998, 69, 1737-1741.

3. Vabrik, R.; Czajlik, I.; Tury, G.; Rusznak, I.; Ille, A.; Vig, A. J Appl Polym Sci 1998, 68, 111-119.

4. Lin, M.-S.; Liu, C.-C.; Lee, C.-T. J Appl Polym Sci 1999, 72, 585-592.

5. Li, Y.; Shen, S.; Liu, Y.; Gao, J. J Appl Polym Sci 1999, 73, 1799-1803.

6. Denq, B.-L.; Hu, Y.-S.; Chen, L.-W.; Chiu, W.-Y.; Wu, T.-R. J Appl Polym Sci 1999, 74, 229-237.
7. Kaji, M.; Nakahara, K.; Endo, T. J Appl Polym Sci 1999, 74, 690-698.

8. Bascom, W. D.; Cottington, R. L.; Jones, L. L.; Peyser, P. J. J Appl Polym Sci 1975, 19, 2425-2432

9. Yee, A. F.; Pearson, R. A. J Appl Polym Sci 1986, $21,2475-2484$.

10. Belot, V.; Corriu, R. J. P.; Leclereq, D.; Mutin, P. H.; Vioux, A. J Polym Sci Polym Chem 1992, 30, 613-623.

11. Matsukawa, K.; Hasegawa, K.; Inoue, H.; Fu! Ida, A.; Arita, Y. J Polym Sci Polym Chem 19\%. 30, 2045-2048.

12. Ramesh Babu, J.; Sinai-Zingde, G.; Riffle, J. S. J Polym Sci Polym Chem 1993, 31, 1645-1651.

13. Lin, S.-T.; Hung, S. K. J Polym Sci Polym Chem $1996,34,869-884$.

14. Lin, S.-T.; Hung, S. K. Eur Polym J 1997, 33, 365373.

15. Sung, P.-H.; Lin, C.-Y. Eur Polym J 1997, 906.

16. Lee, S. S.; Kim, S. C. J Appl Polym Sci 1998, 69, 1291-1300.

17. Shih, W.-C.; Ma, C.-C. M. J Appl Polym Sci 1998, $69,51-58$.

18. Agrawal, J. P.; Venugopalan, S.; Javed A.; Sabane, J. V.; Muralidharan, M. J Appl Polym Sci 1999, 69, 7-12.

19. Alagar, M.; Thanikai Velan, T.V.; Ashok Kunar, A. $\mathrm{J}$ Polym Comp, in press.

20. Woo, M.; Chen, L. B.; Seferis, J. C. J Mater Sci 1987, 22, 3665-3671.

21. Kim, D. S.; Han, M. J.; Lee, J. R. Polym Eng Sci 1995, 35, 1353-1358.

22. Musto, P.; Mariuscelli, E.; Ragosta, G.; Ruscn, P.; Scarinzi, G. J Appl Polym Sci 1998, 69, 102\%, 1042.

23. Han, H. L.; Chern, Y. C.; Li, K. Y.; Hsieh. K. H. J Appl Polym Sci 1998, 70, 529-536.

24. Han, H. L.; Li, K. Y. J Appl Polym Sci 1998, 70, 2635-2645.

25. Crivello, J. V. J Polym Sci Polym Chem 1976, 14, 159-182.

26. Melissaris, A. P.; Mikroyannidis, J. A. J Polym Sci Part A Polym Chem 1988, 26, 1165-117, 